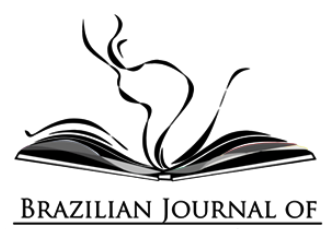

\title{
O INSEGURO DESEMPREGO NA AMÉRICA DO SUL
}

\author{
DESEMPLEO INSEGURO EN AMÉRICA DEL SUR \\ UNSAFE UNEMPLOYMENT IN SOUTH AMERICA
}

\begin{abstract}
Alexandre Sampaio Ferraz iD
Departamento Intersindical de Estatísticas e Estudos Socioeconômicos (DIEESE), Brasil
\end{abstract}

Resumo: O artigo explora os desafios das políticas de proteção social na América do Sul analisando a política do seguro-desemprego, a partir dos modelos chileno e brasileiro. Os antigos desafios da proteção social em um mercado dualista se somam a novos desafios decorrentes das transformações no mercado de trabalho, e do impacto da crise provocada pela pandemia do COVID-19. O texto se baseia em uma pesquisa bibliográfica sobre o seguro-desemprego, e em dados estatísticos. As conclusões apontam para a insuficiência do modelo de contas individuais em substituição ao modelo atualmente adotado no Brasil, para garantir a renda do trabalhador durante o período de busca por um novo emprego, e a suavização da queda da demanda agregada nas crises econômicas. A sugestão é que os países da América Latina adotem a política do seguro-desemprego e, onde existe, que se amplie a cobertura e a duração do benefício. E ainda, que seja criada uma outra modalidade de seguro-desemprego complementar à atual, mas como benefício definido e desvinculado da demissão de um emprego formal, de modo que atenda tanto trabalhadores informais, como formais, na linha da assistência ao desemprego existente em diversos países.

Palavras-chave: $\quad$ Seguro-desemprego; Mercado-de-trabalho; Proteção-social; Informalidade; Políticas Públicas.

Resumen: El artículo explora los desafíos de las políticas de protección social en América del Sur mediante el análisis de la póliza de seguro de desempleo de los modelos chileno y brasileño. Los viejos desafíos de la protección social en un mercado dualista se suman a los nuevos desafíos

\footnotetext{
1 Doutor em Ciência Política pela Universidade de São Paulo (USP). Graduado em Ciências Econômicas pela Pontifícia Universidade Católica (PUC). Pesquisador do Departamento Intersindical de Estatísticas e Estudos Socioeconômicos (DIEESE). E-mail: alexandre@dieese.org.br
} 
derivados de los cambios en el mercado laboral y al impacto de la crisis provocada por la pandemia del COVID-19. El texto se basa en una investigación bibliográfica sobre el seguro de desempleo y en datos estadísticos. Las conclusiones indican la insuficiencia del modelo de cuentas individuales para reemplazar el modelo actualmente adoptado en Brasil, para garantizar el ingreso del trabajador durante el período de búsqueda de un nuevo empleo, y suavizar la caída de la demanda agregada en las crisis económicas. La sugerencia es que los países latinoamericanos adopten la póliza de seguro de desempleo y, donde exista, amplíen la cobertura y duración del beneficio. Todavía más, que se cree otro tipo de seguro de desempleo que complemente al actual, pero como un beneficio definido y separado del despido de un trabajo formal, que atienda tanto a los trabajadores informales como a los formales, semejante a la asistencia por desempleo existente en varios países.

Palabra clave: Seguro de Desempleo; Mercado Laboral; Protección Social; Informalidad; Políticas Públicas.

Abstract: The article explores the challenges of social protection policies in South America by analyzing the Chilean and Brazilian models of unemployment insurance policies. The old challenges of social protection in a dualistic market add up to new challenges resulting from changes in the labor market and the impact of the crisis caused by the COVID-19 pandemic. The text is based on a literature research on unemployment insurance and on statistical data. The conclusions point to the insufficiency of the individual accounts model in substitution to the model currently adopted in Brazil to guarantee the income of the worker while they are seeking for a job and the smoothing the drop of the aggregate demand in the economic crises. The suggestion is that Latin American countries adopt the unemployment insurance policy and, where it exists, that the coverage and duration of the benefit be extended. In addition, another type of unemployment insurance should be created to complement the current one but as a defined benefit and unrelated to the dismissal from a formal job. That will support both informal and formal workers in line with the unemployment assistance existing in several countries.

Keyword: Unemployment Insurance; Labor Market; Social Protection; Informality; Public Policy. 


\section{Introdução}

A realidade dos países latino-americanos é muito diversa apesar de todos compartilharem o passado colonial e o desenvolvimento dependente, expresso na incapacidade de gerar um processo autônomo de desenvolvimento econômico e social. Esta incapacidade se reflete na baixa renda per capita em relação aos países desenvolvidos, e presença significativa, senão predominante, de setores de baixa produtividade e informais.

A baixa renda per capita e a informalidade, que marcam o dualismo no mercado de trabalho (formal/informal), impõe grandes restrições para estruturação e sustentação de políticas de proteção social nesses países. A análise dos programas de seguro-desemprego na América do Sul e seu desempenho durante a crise provocada pela pandemia revelam o alcance e as limitações dessa política nos países em desenvolvimento, ao mesmo tempo que dá as pistas necessárias para construção de um sistema efetivo de proteção social na região.

O artigo se baseia numa pesquisa bibliográfica e em informações secundárias e estatísticas primárias para os casos do Chile e Brasil. O artigo se divide em 6 partes. As duas primeiras traçam um panorama da regulamentação internacional do seguro-desemprego, e sua difusão para América do Sul. As duas partes seguintes tratam de uma breve revisão da literatura, com novas conclusões sobre o impacto do seguro-desemprego no mercado de trabalho e na economia e apresentam a discussão sobre fundos individuais com o papel similar ao do seguro-desemprego. As duas últimas, precedendo a conclusão, abordam a crise do emprego devido à Pandemia e o papel do seguro-desemprego em decorrência da crise, com foco no desempenho da política no Chile e Brasil.

A conclusão reforça a incipiência do seguro-desemprego nos países da América do Sul, principalmente em termos de cobertura, em decorrência do desenho e da alta informalidade no mercado de trabalho. 
Esta deficiência se sobressai nos momentos de crise, como a provocada pela pandemia. O redesenho da política do seguro-desemprego, ampliando sua abrangência e estendendo o período de cobertura coloca como uma solução tanto do ponto de vista do trabalhador individual, como também em termos macroeconômicos.

\section{A regulamentação internacional do seguro-desemprego}

A política do seguro-desemprego é o principal instrumento adotado internacionalmente para proteção ao trabalhador frente ao risco da perda do emprego, inerente à relação de trabalho no capitalismo. O seguro contra o risco do desemprego começou a ser adotado por países europeus ainda antes da primeira Guerra, o que contribuiu para que a Organização Internacional do Trabalho (OIT) defendesse, desde a sua primeira recomendação, o estabelecimento de um sistema efetivo de seguro-desemprego pelos países membros “... quer através de um sistema do Governo ou através de um sistema de subvenções do Governo para associações cujas regras prevejam o pagamento de benefícios aos seus membros desempregados." (OIT, 1919, trad. livre). ${ }^{2}$

O desenho básico do que a entidade passaria a entender como um "sistema efetivo" de seguro-desemprego foi consolidado posteriormente em quatro convenções. A Convenção n. 44, de 1934, determinou que os trabalhadores em desemprego involuntário recebam alguma espécie de benefício desemprego ou abono ou uma combinação dos dois. Em 1952, a Convenção n. 102, definiu os padrões mínimos do benefício desemprego, estipulando que devem ser cobertos pelo benefício ao menos 50\% do total de assalariados.

Em 1982, foi estabelecida a Convenção n. 158, que determina que o trabalhador demitido por iniciativa do empregador tenha direito ao benefício desemprego, seja o seguro-desemprego ou a assistência ao

\footnotetext{
2 No original "either through a Government system or through a system of Government subventions to associations whose rules provide for the payment of benefits to their unemployed members". (OIT, 1019).
} 
desempregado, ou a uma indenização por tempo de serviço, ou uma combinação de benefício e indenização. ${ }^{3}$ Por fim, em 1988, a Convenção, n. 168, tratou novamente da cobertura dos benefícios, estipulando uma cobertura de $85 \%$ de todos os trabalhadores, o mínimo de duração de 6 meses e taxa de reposição de pelo menos de $45 \%$ do salário anterior ou do salário-mínimo.

A OIT teve um importante papel na difusão da política do seguro-desemprego, mas os fatores nacionais e conjunturais foram decisivos no timing de sua adoção e em seu desenho. Os países da América Latina, em particular, vêm demonstrando relutância em ratificar essas orientações e adotar uma política de seguro-desemprego nos moldes preconizados pela OIT e tal como erguida nos países desenvolvidos (OIT, 2017).

O benefício desemprego pode ser dividido em dois tipos: a) o seguro-desemprego propriamente dito e cujo montante variável está vinculado ao salário anterior à demissão e a sua duração ao tempo de emprego; e b) a assistência ao desempregado, que é geralmente uma quantia fixa e exclusiva para os trabalhadores com renda inferior a um valor mínimo, e não vinculada a existência de vínculo anterior no mercado de trabalho (OIT, 2017: 45). Esta diferença contribuiu para que se buscasse financiamento distinto para cada um deles: enquanto o seguro-desemprego é geralmente financiado por contribuições específicas sejam patronais, dos trabalhadores e/ou do governo, a assistência ao desempregado é geralmente financiada por tributos gerais (OZKAN, 2014).

$\mathrm{Na}$ grande parte dos países os benefícios são "mandatórios" obrigatórios e previstos em lei, mas alguns países possuem sistemas voluntários e definidos em convenções coletivas como no chamado Ghent System (OZKAN, 2014). A maioria dos países europeus possui os dois sistemas e, quando se exaure o tempo do seguro-desemprego, o trabalhador automaticamente migra para a assistência ao desempregado,

\footnotetext{
${ }^{3}$ Ao contrário dos dois tipos de benefícios conferidos pelo Estado ou pelos próprios sindicatos, a indenização geralmente é paga diretamente pelas próprias empresas aos trabalhadores (OZKAN, 2014).
} 
que geralmente não tem limitação temporal para sua concessão. A adoção deste modelo híbrido é mais rara em países liberais, como os EUA e a Inglaterra que possuem apenas o seguro-desemprego, ou que adotam apenas a assistência ao desempregado, como na Nova Zelândia e na Austrália (OZKAN, 2014).

Os benefícios monetários ao desempregado são considerados uma política passiva do mercado de trabalho, uma vez que o nível de desemprego é considerado como dado e o dispêndio é uma função direta dele (AZEREDO, 1997). As políticas passivas de mercado de trabalho são de natureza compensatória, dando ao desempregado algum benefício monetário transitório, como no caso do seguro-desemprego. Enquanto as políticas ativas ao invés de tomar o desemprego como exógeno procuram influências a demanda e oferta de mão de obra, como no caso das políticas de qualificação profissionais ou alocação de mão de obra (AZEREDO, 1997:51). ${ }^{4}$

Os países da OCDE, cada vez mais têm dedicado esforços também às políticas ativas do mercado de trabalho, que procuram reduzir o desemprego, como a criação direta de emprego, subsídio ao emprego, treinamento de mão de obra e serviços de realocação de mão de obra. Os dados da OCDE, para 2018, mostram que o gasto com as políticas ativas representava quase metade (47\%) do gasto total.

Entre os países da OCDE, as duas modalidades de benefícios (seguro e assistência) respondem por 92\% do gasto com políticas ativas, que na média foi de 4,4\% do PIB, para 2018. Para comparação, no Chile o gasto ficou em 2,9\% do PIB, e no Brasil apenas 0,5\%. Na América Latina, apenas 12,2\% dos desempregados acessam o benefício, enquanto a média mundial é de 21,8\%, na Europa Ocidental, do Norte e Sul a média é de 46,2\%, e na Europa do Leste é 56,5\% (OIT, 2017: 48). Na maior parte dos países da OCDE, o seguro-desemprego cobre pelo menos 12 meses de desemprego, muitas vezes sendo substituído então pela assistência ao desempregado. Como mostram Ferraz e Oliveira (2015), para o Brasil, e Sehnbruch, Carranza e

\footnotetext{
${ }^{4}$ Ver também Zylberstajn e Netto (1999).
} 
Contreras (2020), para o Chile, nos dois países, tanto a taxa de cobertura é baixa, como o período assegurado para gozo do benefício.

\section{A política do seguro desemprego na américa do sul}

Enquanto todos os países da América Latina possuem algum instrumento de indenização por demissão vinculada ao tempo de serviço, o mesmo não ocorre com os benefícios ao desempregado. O levantamento de Pinto (2016), mostra como a difusão do seguro-desemprego foi incipiente na América Latina. Entre os 19 países do bloco, apenas seis adotam esta política nacionalmente, sendo todos da América do Sul (Argentina, Uruguai, Chile, Brasil, Venezuela, Equador). Bolívia, Paraguai e Peru não possuem seguro-desemprego. Na Colômbia, apesar de não haver seguro-desemprego, um programa de assistência ao desempregado foi criado, em 2002, atendendo inclusive os trabalhadores informais (MEDINA; NÚÑEZ; TAMAYO, 2013).

Mesmo nos países que adotam o seguro-desemprego, a cobertura tende a ser muito baixa, uma vez que o mercado informal é parte expressiva do mercado de trabalho. A cobertura efetiva dos desempregados, pelos dados da OIT (2017), é maior no Chile, e em certa medida no Uruguai, mas muito reduzida na Argentina, no Brasil e principalmente no Equador e na Colômbia (Gráfico 1). 
Gráfico 1 - Cobertura Efetiva do Benefício Desemprego em países selecionados.

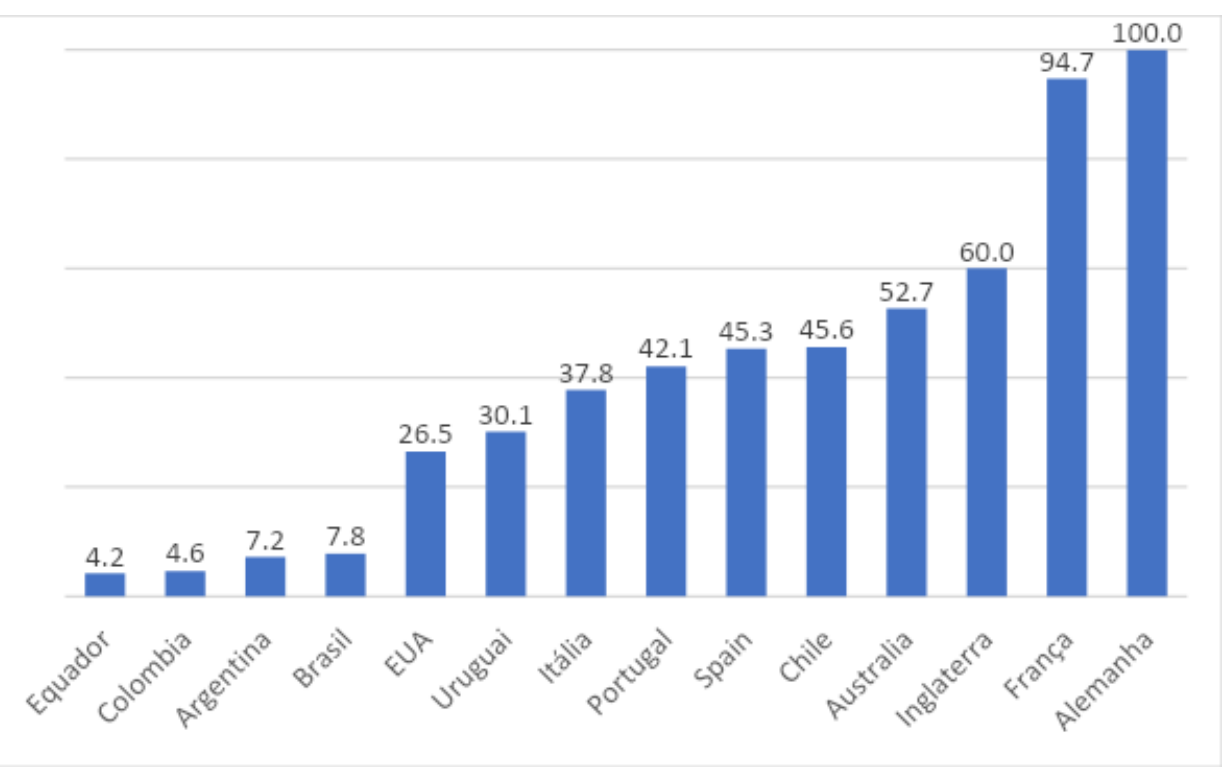

Fonte: OIT (2017). A cobertura efetiva indica a proporção de beneficiários de fato sobre o total de desempregados (elegíveis ou não).

No caso do seguro-desemprego, o mix de financiamento varia de país para país, com o Estado sendo responsável geralmente por cobrir déficits (ESSER, 2013; AMORIN; BILO, 2019). Nos países da América do Sul este mix se compõe da seguinte forma: no Chile, Uruguai, Equador e Venezuela há contribuição direta dos trabalhadores para financiar os benefícios ao desemprego; enquanto na Argentina, Brasil, e Colômbia as contribuições são feitas apenas pelos empregadores (PINTO, 2016; VELÁSQUEZ, 2010; MEDINA; NÚÑEZ; TAMAYO 2013).

No Brasil, o seguro-desemprego é parcialmente contributivo, uma vez que diversas categorias de trabalhadores, cujas empresas estão isentas da contribuição para o Fundo de Amparo ao Trabalhador (FAT), podem acessar o benefício. ${ }^{5}$ A contribuição para o seguro-desemprego vem do Programa de Integração Social (PIS) e é repassada para o FAT, cuja gestão e regulamentação é realizada por órgão tripartite. As alíquotas do PIS podem

\footnotetext{
${ }^{5}$ Os dados da Receita Federal mostram uma desoneração de R\$ 12,8 bilhões do PIS/PASEP, em 2017, para uma arrecadação de 63,4 bilhões, direcionada principalmente para a agroindústria e indústria de medicamentos, e as microempresas e empreendedores individuais.
} 
incidir sobre a folha de salário, no caso de entidades sociais, e sobre o faturamento ou receita no caso de pessoas jurídicas de direito privado. ${ }^{6}$

No Chile, após a adoção do sistema de contas individuais, em 2002, se arquitetou um sistema misto. $O$ seguro-desemprego é baseado no sistema de contas individuais e financiado pelo trabalhador com contribuição de 0,6\% do salário, e por uma contribuição do empregador de 1,6\% sobre a mesma base. Enquanto o benefício de assistência ao desemprego é financiado pela contribuição patronal de 0,8\% sobre a folha destinada ao "Fundo de Solidariedade". O governo entra como garantidor das contas e, também, com a contribuição anual de um montante fixo para o fundo solidário (SEHNBRUCH; CARRANZA; CONTRERAS, 2020).

As contas de poupança individual são mais comuns, mas geralmente estão vinculadas à indenização por demissão, como no caso de Brasil, Peru, Colômbia e Venezuela (PINTO, 2016; VELÁSQUEZ, 2010). No Chile e Equador adota-se este sistema para o seguro-desemprego, sendo que no Chile ele funciona como a assistência ao desempregado dos países da OCDE, e é acionado quando esgota a poupança individual dos trabalhadores que necessitam do seguro-desemprego (SEHNBRUCH; CARRANZA; CONTRERAS, 2020). Apenas Uruguai, Bolívia e Paraguai não possuem este tipo de benefício de proteção ao desemprego, sendo que os dois últimos chamam atenção por não possuir nenhuma política de benefício desemprego.

\section{$4 \quad$ O seguro desemprego e seus críticos}

A política de seguro-desemprego possui diversas virtudes que levaram a sua difusão na Europa e América do Norte. O seguro-desemprego funciona como um estabilizador automático da economia, suavizando a queda na demanda agregada em períodos de recessão, ao mesmo tempo em que permite a garantia de uma renda

\footnotetext{
${ }^{6}$ Este tributo recai sobre o faturamento das empresas com uma alíquota entre 1,65\% e 0,65\%, ou 1\% sobre a folha de pagamento no caso de entidades do terceiro setor, sem fins lucrativos etc.
} 
mínima principalmente ao trabalhador demitido sem justa causa. Ao garantir esta renda, o seguro permite que o trabalhador tenha mais liberdade para buscar uma nova colocação, sem ter que reduzir drasticamente seu consumo ou aceitar uma ocupação com salário e funções incompatíveis com sua qualificação, ou reingressar no mercado de trabalho informal.

O papel do seguro-desemprego sobre a demanda agregada defendido por Keynes na saída da crise de 1929 contribuiu para que fosse considerado umas das principais políticas do Estado de Bem-Estar. Keynes não era um entusiasta das potencialidades libertadoras do seguro-desemprego e do Estado de Bem-Estar, mas sim da ideia de um "mecanismo para gerar renda permanente fora do mercado" (AFONSO, 2018).

O foco de Keynes não era libertar os trabalhadores da disciplina do mercado. O potencial emancipatório do seguro-desemprego, não deve ser ignorado, como mostra Costa Esping-Andersen. O seguro-desemprego é um dos fatores fundamentais na composição do índice de "desmercantilização" do trabalho, utilizado na sua tipologia de Estados de Bem-estar: “"'Desmercantilização ocorre quando um serviço é prestado por uma questão de direito, e quando uma pessoa pode manter uma vida sem dependência do mercado"" (ESPING-ANDERSEN, 1990: 22, trad. livre). ${ }^{7}$ Mas como ele mesmo salienta, benefícios residuais, como no caso da assistência ao desemprego são incapazes de atingir este objetivo, sendo característico do modelo liberal de Estado de Bem-Estar: “... a mera presença de assistência social ou de seguros pode não necessariamente trazer significativa de-mercantilização se eles fazem indivíduos não substancialmente emancipar da dependência do mercado." (ESPING-ANDERSEN, 1990: 22, trad. livre). ${ }^{8}$

\footnotetext{
${ }^{7}$ No original: "De-commodification occurs when a service is rendered as a matter of right, and when a person can maintain a livelihood without reliance on the Market." (ESPING-ANDERSEN, 1990: 22).

${ }^{8}$ No original: "... The mere presence of social assistance or insurance may not necessarily bring about significant de-commodification if they do not substantially emancipate individuals from market dependence." (ESPING-ANDERSEN, 1990: 22).
} 
A liberdade e autonomia dada pelo seguro-desemprego ao trabalhador contribui para aproximá-lo trabalhador do pressuposto do modelo racional maximizador no mercado de trabalho, em que ele escolhe entre lazer e trabalho. Um pressuposto muito irrealista especialmente para os trabalhadores com baixas economias ou riqueza, cujo incentivo é aceitar qualquer trabalho para não ter a renda reduzida a valores aquém do mínimo para subsistência. O que faz com que esta descoberta seja ainda mais relevante nos países de baixa renda per capita e, portanto, de baixo nível de poupança.

Provido desta liberdade e autonomia dada pelo seguro-desemprego no interlúdio entre um emprego e outro, o trabalhador tende a conquistar melhores salários e a buscar maior escolaridade (ULYSSEA, 2008; ACEMOGLU, 2000). Daron Acemoglu, em uma estudo sobre o seguro-desemprego nos EUA, com foco em trabalhadores de baixa qualificação, mostra que um aumento no seguro-desemprego (número de beneficiários e duração) “... torna os trabalhadores mais dispostos a buscar salários mais altos e empregos mais específicos (...) porque esses empregos envolvem muito risco de desemprego" (ACEMOGLU, 2000: 1201. trad. livre). ${ }^{9}$ O incremento na probabilidade de um bom matching orienta também as empresas em fornecer melhores empregos, e promove aumento do consumo e dos salários, contribuindo também para o aumento do emprego (ACEMOGLU, 2000: 1214).

Como observam Zylberstajn e Netto (1999: 138), as teorias de "job-search" tendem a atribuir um efeito perverso ao seguro-desemprego, justamente por aumentar o salário de reserva, reduzindo o incentivo para que o trabalhador aceite logo um emprego mesmo num patamar que considera baixo de salários, e reduzindo o nível de emprego, devido ao aumento de salário por parte das firmas a fim de atrair os trabalhadores "desencorajados". As conclusões de Acemoglu contestam a tese de que por conta da seleção adversa o benefício contribui para ineficiência do

\footnotetext{
${ }_{9}^{9}$ No original: "makes workers more willing to seek higher wages and more specific Jobs (...) because these jobs entail too much unemployment risk" (ACEMOGLU, 2000: 1201).
} 
mercado de trabalho e afeta negativamente o salário do trabalhador ao reduzir seu esforço para procurar emprego: "Portanto, nossa análise sugere que grande parte do que geralmente é rotulado de risco moral pode ser motivado pela disposição dos trabalhadores mais bem segurados de buscar empregos com salários mais altos" (ACEMOGLU, 2000: 1214. trad. livre). ${ }^{10}$

Inspirado nessas análises, Gabriel Ulyssea (2008) mostra que o seguro-desemprego pode ser visto como um subsídio ao trabalhador, mas também ao empregador que contrata no mercado formal. O efeito do subsídio para contratação de trabalhadores formais melhora a composição da força de trabalho e incentiva a formalização, ao invés de elevar a duração e a taxa de desemprego como é corrente na literatura que foca na seleção adversa, ou moral hazard (ULYSSEA, 2008: 543). Para Ulyssea (2008: 528): "... uma elevação substancial no seguro-desemprego produziria um pequeno aumento no grau de formalização e uma ligeira redução no grau de informalidade e na taxa de desemprego.", aumentando a produtividade e o produto. Além de contribuir para uma redução do tempo de desemprego (ULYSSEA, 2008: 528).

Ao subsidiar o trabalhador durante o desemprego e na busca por um novo trabalho o seguro-desemprego evita o desalento, ou a saída do mercado de trabalho, e contribui para um aumento da taxa de participação (ATKINSON; MICKLEWRIGHT, 1991: 1722). Como observa Hirata e Machado (2010), o custo do desemprego aumenta com o tempo empurrando o trabalhador para o mercado informal ou para fora do mercado de trabalho. O subsídio aumenta as chances de um bom matching, incentivando o investimento do trabalhador em qualificação para melhores empregos e no empenho de longo prazo para obtê-los.

Essas conclusões são apoiadas também pela tese de Margolis (2008), para quem o seguro-desemprego, a indenização e a contribuição às contas individuais do Fundo de Garantia por Tempo de Serviço (FGTS) aceleram a

\footnotetext{
${ }^{10}$ No original: "Therefore, our analysis suggests that a large part of what is usually labeled moral hazard, may be driven by the willingness of better-insured workers to seek higher wage Jobs" (ACEMOGLU, 2000: 1214).
} 
transição para o trabalho formal e desaceleram para o trabalho informal no Brasil. O seguro-desemprego funciona, assim, como uma proteção contra o ciclo vicioso dos "bad jobs". Isso torna a política atraente para os países latino-americanos, onde predomina baixa qualificação, grande número de empregos informais, e alta rotatividade da mão de obra, o que, por sua vez, desincentiva o investimento em qualificação.

Da perspectiva macroeconômica, existem evidências robustas de que o seguro-desemprego é eficiente como estabilizador automático da economia, contribuindo para sustentar a demanda agregada em tempos de crise, com resultado positivo sobre o nível de emprego e a lucratividade das empresas." Outros trabalhos têm mostrado também a eficiência do seguro-desemprego na redução da pobreza, com efeitos positivos inclusive sobre a saúde do trabalhador (GABE; WHITTAKER, 2012; RENAHY; MITCHELL, 2018).

Apesar dessas evidências, grande parte dos trabalhos sobre 0 seguro-desemprego tem se concentrado no custo potencial das distorções que pode causar no mercado de trabalho, seja desincentivando o trabalhador a procurar e aceitar um novo emprego, ou mesmo induzindo-o a trocar seu trabalho pelo desemprego remunerado (ATKINSON; MICKLEWRIGHT, 1991: p. 1681). Esses trabalhos têm sido relevantes na análise do seguro-desemprego na América Latina, em particular do Brasil, o que tem levado alguns pesquisadores a proporem o seguro baseado em contas de poupança individuais para contornar este problema.

Nesta abordagem, Barros, Corseuil e Foguel (2009) mostram que quase 50\% dos beneficiários do seguro-desemprego continuaram a trabalhar sem contrato formal. O benefício representava $1 / 3$ da renda familiar das famílias pobres, que respondiam por 40\% das famílias com desempregados na amostra. No período analisado, 23\% das famílias dos beneficiários se encontravam na pobreza, e outros 5\% em nível de indigência (BARROS, CORSEUIL; FOGUEL, 2009, p. 10). Apesar do benefício

\footnotetext{
${ }^{1}$ Kekre (2021), Schmieder; von Wachter; Bender (2010), Di Maggio; Kermani (2016), Hellwig (2021).
} 
ter uma taxa de reposição de $100 \%$ da renda na base da pirâmide salarial, fica clara a importância do seguro para tirar os trabalhadores da pobreza e permite a busca de trabalho compatível sem a necessidade de se dirigir ao mercado informal.

Os autores mostram que a possibilidade de os trabalhadores receberem o seguro-desemprego, separado ou juntamente com o acesso ao fundo de poupança por demissão sem justa causa (FGTS) e a multa rescisória incentiva tanto trabalhadores como firmas à demissão. Nessa linha, Cristiano Carvalho mostram que 34\% dos beneficiários se empregam no setor informal no mês subsequente, e uma parte relevante força a demissão para acessar o benefício: "73\% das demissões sem justa causa são induzidas por parte dos trabalhadores" (CARVALHO, 2017, p. 79).

\section{$5 \quad$ Fundos individuais de seguro-desemprego}

Os supostos incentivos adversos do seguro-desemprego no Brasil, que estimulariam uma redução no período de emprego e prolongariam o período de desemprego, tal como sugerido pela literatura internacional, se somariam à maior probabilidade de o trabalhador reingressar no mercado informal acumulando o benefício com o rendimento no novo emprego informal. Frente a essas evidências, alguns autores têm proposto um redesenho do sistema de proteção em direção a uma unificação dos benefícios, inspirada no modelo chileno (CAMPOS et al., 2019; BARBOSA, 2017).

A alternativa das contas individuais foi apresentada inicialmente por Altman e Feldstein (2007), como forma de corrigir distorções e, também, reduzir os custos do seguro-desemprego para o Estado, uma vez que, nos EUA, país objeto da análise dos autores, os problemas de déficit são constantes. A ideia básica é que ao invés de o empregador ou toda sociedade financiarem o seguro-desemprego, isso seja feito pelo próprio empregado direta ou indiretamente de forma individual. Caso o trabalhador não precise usar a poupança forçada para financiar sua queda 
de renda durante o desemprego, pode guardá-la para aposentadoria, ou até como no caso do Brasil e outros países, para comprar imóveis (BARBOSA, 2017: 8).

Segundo a OIT este tipo de seguro-desemprego não preenche os requisitos das suas Convenções, uma vez que promove seguro limitado para os trabalhadores que têm dificuldade em permanecer por longos períodos no mesmo emprego, como aqueles em contratos temporários e sazonais, e principalmente, em mercados de trabalho com alta rotatividade. São esses trabalhadores de baixa renda que acabam sendo incapazes de constituir poupança suficiente para arcar com os períodos de inatividade (OIT, 2017: 45).

Ao estudar o caso chileno, Sehnbrunch, Carranja e Contreras (2020) mostra que a cobertura do seguro é baixa entre os trabalhadores que requerem o benefício, principalmente aqueles com contratos temporários (SEHNBRUNCH; CARRANJA; CONTRERAS, 2020: p. 26). Ainda que no mercado formal, o trabalhador que fica pouco tempo no mesmo emprego acaba por não conseguir constituir uma poupança suficiente para usufruí-la durante o período de cesantía. Segundo o autor, a alta rotatividade no mercado de trabalho e o desenho de restrições muito duras para acessar o benefício assistencial, acabam fazendo com que o sistema "exacerbe as desigualdades no mercado de trabalho" (SEHNBRUNCH; CARRANJA; CONTRERAS, 2020: p. 27). ${ }^{12}$

O efeito da rotatividade do mercado de trabalho sobre as contas é claro, mas a própria rotatividade é afetada pelo desenho do seguro-desemprego. O mix entre o financiamento do seguro por contas individuais e um fundo público ganhou destaque em trabalhos recentes que procuram reformar e expandir a estrutura dos sistemas de proteção social (SETTY, 2017). Nesta linha, Campos et al. (2019) sugere a alteração na complementaridade entre o seguro-desemprego e a indenização por

\footnotetext{
${ }^{12}$ O trabalho de Montt, Ordóñez e Silva (2020, p. 17): também evidenciou a baixa cobertura do programa: “... al primer trimestre del 2020 un 31\% de los ocupados no tienen ningún tipo de cobertura frente a la desocupación y un $13 \%$ cotiza en el sistema, pero no cumple las condiciones de elegibilidad. Un $16 \%$ tiene indemnizaciones propias.".
} 
tempo de serviço no Brasil, de modo que os trabalhadores acessem primeiro suas próprias economias no FGTS para só depois, caso permaneçam desempregados, possam acessar o seguro-desemprego (CAMPOS et al., 2019: 36). Contudo, os próprios autores alertam que a poupança individual do FGTS não é suficiente para "proteção adequada" do trabalhador frente ao desemprego, devendo ser combinada com o seguro-desemprego.

\section{Efeitos da crise sobre o mercado de trabalho}

O comportamento da taxa de desemprego na pandemia mostra uma clara correlação entre a rigidez no mercado de trabalho e a variação no desemprego. Países com maior rigidez em geral tendem a ter uma menor variação no nível de emprego, o que se traduz no aumento da proteção ao trabalhador frente ao desemprego causado pela crise (OECD, 2020). Na Europa, onde as restrições para demissão são maiores, o desemprego em 2020 cresceu 9\% em relação ao ano anterior, enquanto entre os países da OCDE o crescimento foi de 37\%.

Nos 10 países da América do Sul, exceptuando-se Guianas e Suriname, a média do crescimento do desemprego ficou em 43\%, de 2019 para 2020. A realidade de cada país da região é muito diversa, mas chama atenção no bloco a alta taxa de desemprego, com uma taxa média de 9,7\%. ${ }^{13}$ As taxas, contudo, escondem outra característica importante do mercado de trabalho entre esses países. Praticamente todos têm taxas de informalidade superior a 30\%, e na maioria das vezes maior do que 50\%, com exceção do Chile, com 29\% de informais em 2019, e do Uruguai, com 23\%. Na maior parte dos países a taxa média de informalidade entre os ocupados é de $60 \%$, como pode ser visto no gráfico abaixo.

\footnotetext{
${ }^{3}$ Para comparação, nos EUA a taxa ficou em 8,3\%, enquanto a Alemanha registrou 4,3\%.
} 
Gráfico 2 - Taxa de desemprego e Informalidade na América do Sul

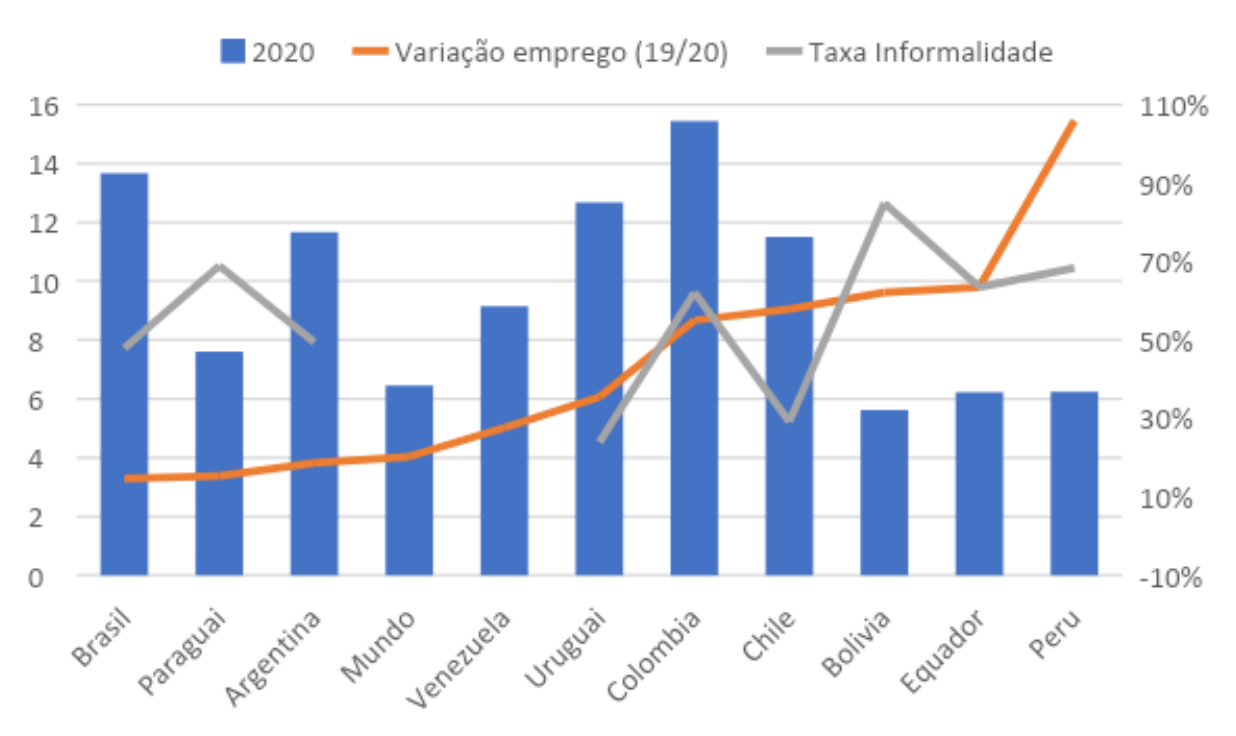

Fonte: OIT (2021) .

A alta taxa de informalidade no mercado de trabalho se traduz no baixo nível de proteção social, uma vez que o trabalhador informal não conta com as políticas seguro-desemprego, auxílio ao desemprego e indenização por tempo de trabalho. Bolívia, Peru, Equador e Colômbia têm as maiores taxas de informalidade do bloco, superior a $60 \%$ dos ocupados, e tiveram aumento do desemprego em 2020 maior que a média dos países analisados. Mas existem exceções, como é o caso do Chile, que tem uma das menores taxas de informalidade do bloco, mas exibiu um aumento relativamente alto da taxa de desemprego.

\section{Proteção ao trabalhador em tempos de crise}

O Brasil perdeu cerca de 2 milhões de empregos nos 12 meses entre fevereiro de 2012 até janeiro de 2021, chegando a 14,3 milhões de desempregados segundo os dados do Instituto Brasileiro de Geografia e Estatística (IBGE)..$^{14}$ A pandemia pegou um país já debilitado pela crise

\footnotetext{
14 Os dados do IBGE referidos nesta seção são todos provenientes da Pesquisa Nacional de Amostras ao Domicílio Contínua - Mensal (PNADC). Os dados estão disponíveis em: https://www.ibge.gov.br/estatisticas/sociais/trabalho/9171-pesquisa-nacional-por-amostra-de-domicilios-continuamensal.html.
} 
econômica que atingiu o mercado de trabalho em 2015. Os dados do IBGE mostram que entre 2018 e 2019, uma leve melhora no mercado de trabalho levou o índice de desemprego para 11\% da força de trabalho. Mas a queda no desemprego no setor privado foi puxada pelo emprego sem carteira assinada e pelo emprego por conta própria sem registro formal. Nada menos do que 62\% das vagas no setor privado foram para o trabalho informal, que não dispõe de proteção social.

A taxa de desemprego cresceu 27\% de janeiro a janeiro, de 2020 para 2021, chegando a 14,1\%, segundo os dados do IBGE. E seria maior não fosse a redução da população economicamente ativa, com a retirada de 5,8 milhões de trabalhadores do mercado de trabalho em consequência da Pandemia. Os trabalhadores informais foram os mais atingidos pela crise, segundo dados da mesma pesquisa, pois o número de empregados no setor privado sem carteira caiu 16\%, contra 11,6\% entre os com carteira assinada. Entre trabalhadores e patrões informais, o Brasil perdeu 3 milhões de empregos, ou quase 3,8 milhões se incluirmos o emprego doméstico sem carteira.

Os dados do Ministério da Economia, por sua vez, mostram que o número de beneficiários do seguro-desemprego, contudo, se manteve praticamente constante, com um acréscimo de apenas 143,4 mil trabalhadores nos 12 meses contados entre março de 2020 e fevereiro de 2021, um crescimento de 2,4\% em relação ao ano anterior. ${ }^{15}$ No mesmo período, o nível de emprego no setor privado com carteira passou de 33,6 para 29,8 milhões, uma queda de 11,5\%, também segundo o IBGE. Ou seja, menos da metade desses desempregados do setor privado formal conseguiram acessar o seguro-desemprego.

A taxa de cobertura do seguro no período foi de $41 \%$, ou seja, $41 \%$ dos trabalhadores com contrato formal de trabalho demitidos sem justa causa receberam o seguro-desemprego. Ao mesmo tempo, cerca de 8,8 milhões dos vínculos interrompidos não acessaram o seguro. Ao longo do ano,

\footnotetext{
${ }^{15}$ Os dados do Seguro Desemprego provenientes do Ministério da Economia foram acessados por meio do sítio do Programa de Disseminação das Estatísticas do Trabalho. Os dados estão disponíveis em: http://pdet.mte.gov.br/component/content/article?id=1778.
} 
contudo, a dinâmica do mercado de trabalho é diversa, em média apenas $4 \%$ dos desempregados se beneficiaram do seguro-desemprego mensalmente, chegando à máxima de 7\% em abril de 2021.

Ao contrário de outros países, no Brasil a crise não levou ao aumento do número de parcelas pagas e do número de beneficiários do seguro-desemprego. Os dados do Ministério da Economia mostram que o país registrou um decréscimo no número de beneficiários, em 2020, com 6,2 milhões de beneficiários frente ao ano anterior. Apenas nos meses de abril, maio e junho de 2020, esta tendência se inverteu. No FGTS, o número de saques por demissão sem justa causa caiu 5\%, totalizando 15,9 milhões, em 2020.16 As alterações nas regras entre 2015, aumentando o período de contribuição mínimo para acessar o benefício, e restringindo as parcelas já havia reduzido o volume de beneficiários, assim como a própria redução do estoque de trabalhadores formais naquele ano não ajudaram na crise de 2020.

Em comparação, o Chile perdeu 942 milhões de empregos entre fevereiro de 2020 e janeiro de 2021, segundo dados da Encuesta Nacional de Empleo (ENE). ${ }^{17}$ O número de desocupados cresceu 20\% no período, com 147 milhões de "novos" desempregados. A queda foi muito maior entre os trabalhadores domésticos (33\%), e os trabalhadores por conta própria (11\%), do que os assalariados do setor privado (10\%). A taxa de desocupação em dezembro de 2020 fechou em 10,3\%, depois de atingir a máxima de 13,1\% em julho de 2020.

O número de beneficiários do seguro chileno, contudo, cresceu $61 \%$ de 2019 para 2020. A proporção de beneficiários em relação ao total de desempregados foi de 32\% em média em 2020. Em média 64\% dos beneficiários sacaram de suas contas individuais, $24 \%$ do fundo solidário e $11 \%$ de ambas as modalidades. Atualmente, cerca de 56\% dos trabalhadores chilenos contribuem para os fundos individuais. A taxa de recusa do

\footnotetext{
${ }^{16}$ Dados disponíveis no sítio do FGTS: https://www.fgts.gov.br/Pages/numeros-fgts/passivo-fgts.aspx.

${ }^{17}$ Os dados do Instituto Nacional de Estadísticas estão disponíveis no sítio: $\underline{\text { https://stat.ine.cl/?lang=es. }}$
} 
benefício tem sido de 13\%, basicamente em razão da insuficiência de um mínimo de contribuições prévias.

A crise obrigou tanto o Chile, como o Brasil a criar programas emergências para os trabalhadores e famílias pobres, suplementares aos já existentes como o Bolsa Família ou Chile Solidário. O auxílio emergencial no Brasil chegou a beneficiar 68 milhões de pessoas em 2020, e o Bônus Covid no Chile, cerca de 1,5 milhões. O sucesso desses programas que atingiram muito mais famílias do que as transferências para redução da pobreza revelou a precariedade do emprego e da renda de milhões de trabalhadores informais, não cobertos pelos programas de proteção existentes.

Os dois países criaram também programas de lay off para ajudar empresas e trabalhadores a suportar o período mais duro da crise, e permitiram saques extraordinários das contas individuais do fundo de cesantía no caso do Chile, ou do Fundo de Garantia por Tempo de Serviço, no caso do Brasil. A flexibilização das regras do seguro-desemprego no Chile foi importante para ampliação dos beneficiários. A lei 21.263 de setembro de 2020, reduziu pela metade o número de contribuições mínimas nos últimos 12 meses para ter acesso ao benefício ou a apenas três antes da demissão, aumentou a duração do benefício em até 2 meses, e a taxa de recomposição salarial, além de introduzir o seguro-desemprego para o trabalhador doméstico.

\section{Conclusão}

A pandemia provocada pela COVID-19 escancarou a deficiência da rede de proteção social nos países latino-americanos, em particular das políticas de proteção ao risco de desemprego. Esses países contam com alta flexibilidade laboral, completa ausência de benefícios desemprego, ou baixa cobertura onde existem.

Os modelos chileno e brasileiro conjugam cada um ao seu modo o seguro-desemprego, com contas individuais de poupança. Mas os dois 
modelos falham ao resultarem em baixa cobertura, combinada com uma reduzida duração dos benefícios, o que fez com que os programas não respondessem de forma adequada às necessidades advindas da pandemia, deixando desprotegidos os trabalhadores, ou levando a flexibilizações extraordinárias.

A "descoberta" nos dois países de um público altamente vulnerável que foi objeto central das iniciativas extraordinárias de proteção a renda e ao emprego e o relativo sucesso dessas medidas nos dois países deixam uma pista importante para o desenho de políticas mais efetivas e inclusivas de proteção ao trabalhador frente ao desemprego. O desenho do seguro-desemprego não pode atender apenas os empregados com vínculos formais, mas tem que suportar também os trabalhadores precários. Como ocorre nos países em que a assistência ao desempregado não é condicionada a contribuição prévia.

Ao invés de buscar um desenho inovador como o Chileno, mas que mantém a baixa abrangência e cobertura, a América do Sul e os demais países da América Latina poderiam seguir o caminho já trilhado pelos países que conseguiram construir economias com elevado padrão de bem-estar e desenvolvimento, apostando na consolidação de programas de proteção contra o risco de desemprego que tenham potencial tanto para suavizar as crises econômicas frequentes na região, como para alavancar a formalização e o investimento em qualificação e bons empregos. Para isso é preciso implementar os programas preconizados pela OIT, e ampliar a cobertura, a duração e a integração com as políticas ativas de proteção ao trabalhador.

\section{Referências}

ACEMOGLU, Daron, e SHIMER, Robert. Productivity Gains from Unemployment Insurance. European Economic Review, vol. 44, pp. 1195-1224, 2000. doi.org/10.1016/S0014-2921(00)00035-0.

AFONSO, R. José. Desenvolvimento, trabalho e seguro social: volta a Keynes para enfrentar novos desafios. Revista do BNDES, Rio de Janeiro, v. 25, n. 
50, p. 203-245, dez. 2018. Disponível em: http://web.bndes.gov.br/bib/jspui/handle/1408/16842 Acesso em: 09 out. 2021.

ALTMAN, Daniel; FELDSTEIN, Martin. Unemployment Insurance Savings Accounts, 21 Tax Policy and the Economy, vol. 21, n. 1, mai 2007, pp. 35-63. doi.org/10.1086

AMORIN, Bruno; BILO, Charlotte. Seguro-desemprego ao redor do mundo: uma visão geral. IPEA. Diretoria de Estudos e Políticas Sociais, n. 55, julho de 2019. Disponível em: http://repositorio.ipea.gov.br/handle/11058/9308. Acesso em: 09 out. 2021.

ATKINSON, Anthony; MICKLEWRIGHT, John. Unemployment Compensation and Labor Market Transitions: A Critical Review. Journal of Economic Literature, 29(4), 1679-1727, 1991. Disponível em: http://www.jstor.org/stable/2727794. Acesso em: 09 out. 2021.

AZEREDO, Beatriz. Políticas públicas de emprego: tendências e possibilidades. São Paulo em Perspectiva, vol. 11, n. 4, pp. 47-59, 1997. Disponível em: https://produtos.seade.gov.br/produtos/spp/v11n04/v11n04_06.pdf. Acesso em: 04 set. 2021.

BARBOSA, Ana; FOGUEL, Miguel; BILO, Charlotte. FGTS e fundos individuais de seguro-desemprego: análise comparativa entre países e efeitos no mercado de trabalho. Mercado de trabalho: conjuntura e análise. IPEA, $n$. 63, p. 47-62, 2017. Disponível em: http://repositorio.ipea.gov.br/bitstream/11058/8128/1/bmt_63_FGTS.pdf. Acesso em: 04 set. 2021.

BARROS, Ricardo; COURSEUL, Carlos; FOGUEL, Miguel. Os incentivos adversos e a focalização dos programas de proteção ao trabalhador no Brasil. Planejamento E Políticas Públicas, n. 22. 2009. Disponível em: http://www.ipea.gov.br/ppp/index.php/PPP/article/view/79 . Acesso em: 09 oct. 2021

CAMPOS, André; et al. Instituições trabalhistas e produtividade do trabalho: uma análise do caso brasileiro. In: Desafios da nação, v.2, IPEA, 2019.

CARVALHO, Cristiano. Efeitos adversos da legislação do seguro-desemprego: evidência sobre o Brasil [Dissertação]. São Paulo: Universidade de São Paulo, Faculdade de Economia, Administração e Contabilidade. 2017. doi:10.11606/D.12.2017.tde-17082017-113503.

DI MAGGIO, Marco; KERMANI, Amir. The Importance of Unemployment Insurance as an Automatic Stabilizer. Harvard Business School Working Paper, No. 17-009, July 2016. http://dx.doi.org/10.3386/w22625

ESPING-ANDERSEN, Gosta. The Three Worlds of Welfare Capitalism. Polity Press. 1990. 
ESSER, Ingred; et al. Unemployment benefits in EU Member States. European Commission, Brussels. Jul. 2013. Disponível em: http://hdl.handle.net/10419/91759. Acesso em: 09 oct. 2021.

FERRAZ, Alexandre; OLIVEIRA, Tiago. Mercado de trabalho e programas de seguro-desemprego: uma análise comparativa entre o Brasil e países selecionados da OCDE. Caderno do Observatório Nacional do Mercado de Trabalho. Dieese, vol. 1, pp. 61-84. 2015. Disponível em: https://www.dieese.org.br/livro/2016/cadernoObservatoNacionalVol1/index.h tml?page=4. Acesso em: 09 oct. 2021.

GABE, Thomas; WHITTAKER, Julie. Anti Poverty Effects of Unemployment Insurance. CRS Report for Congress. Prepared for Members and Committees of Congress, 16 oct. 2012. Disponível em: https://hdl.handle.net/1813/7932. Acesso em: 09 oct. 2021.

HELLWIG, Klaus-Peter. Supply and Demand Effects of Unemployment Insurance Benefit Extensions: Evidence from U.S. Counties. IMF Working Papers. WP/21/70. mar. 2021. Disponível em: https://www.imf.org/en/Publications/WP/Issues/2021/03/12/Supply-and-Dem and-Effects-of-Unemployment-Insurance-Benefit-Extensions-Evidence-fro m-U-S-50112. Acesso em: 09 oct. 2021

HIRATA, Guilherme; MACHADO, Ana. Escolha ocupacional e transição no Brasil Metropolitano: uma análise com ênfase no setor informal. Economia Aplicada. Ribeirão Preto, v. 14, n. 4, p. 299-322. dez.2010. http://dx.doi.org/10.1590/S1413-80502010000400003.

KEKRE, Rohan. Unemployment Insurance in Macroeconomic Stabilization. University of Chicago, Becker Friedman Institute for Economics Working Paper, N. 28, mar. 2021. http://dx.doi.org/10.2139/ssrn.3795662.

MARGOLIS, David. Unemployment Insurance Versus Individual Unemployment Accounts and Transitions to Formal Versus Informal Sector Jobs, Working Papers 2008-35, Center for Research in Economics and Statistics. 2008. Disponível em: http://crest.science/RePEc/wpstorage/2008-35.pdf. Acesso em: 09 oct. 2021.

MEDINA, Carlos; NÚÑEZ, Jairo; TAMAYO, Jorge. The Unemployment Subsidy Program in Colombia: an assessment. Inter-American Development Bank. IDB working paper series, WP 369, mai. 2013. Disponível em: http://www.banrep.gov.co/docum/ftp/be_750.pdf Acesso: 09 oct. 2021.

MONTT, Guillermo; ORDÓÑEZ, Félix; SILVA, Ignacio. Protección ante la desocupación en Chile. Desafíos y oportunidades luego de una crisis sistémica. Informes Técnicos 15. Santiago. OIT. 2020. Disponível em:. https://www.ilo.org/santiago/publicaciones/informes-tecnicos/WCMS_75591 9/lang--es/index.htm. Acesso em: 09 oct. 2021. 
OECD. Economic Outlook, Volume 2020 Issue 1: Preliminary version, OECD Publishing, Paris, doi.org/10.1787/0d1d1e2e-en.

OIT. R001 - Unemployment Recommendation, 1919 (No. 1). Disponível em: https://www.ilo.org/dyn/normlex/en/f?p=1000:12100:9631294416643::NO::P121 OO_SHOW_TEXT:Y: Acesso em: 09 oct. 2021.

OIT. World Social Protection Report 2017-19: Universal social protection to achieve the Sustainable Development Goals. International Labour Office Geneva: ILO, 2017. https://www.social-protection.org/gimi/gess/RessourcePDF.action?id=5488 7. Acesso em: 09 oct. 2021.

OIT. (Organização Internacional do Trabalho). Employment by sex and age - ILO modelled estimates. ILOSTAT database, Disponível em: https://ilostat.ilo.org/data. Acesso em: 29 jun. 2021.

OZKAN, Umut. Comparing formal unemployment compensation systems in 15 OECD countries. Social Policy \& Administration, vol. 48, n.1, pp. 44-66. 2014. doi.org/10.1111/spol.12010.

PINTO, Mario. An analysis of unemployment protection in Latin America. In: ISGUT, Alberto; WELLER, Juergen (Eds). Protection and training: Institutions for improving workforce integration in Latin America and Asia, ECLAC Books. 2016.

RENAHY, Emilie; MITCHELL, Christiane. Connections between unemployment insurance, poverty and health: a systematic review. The European Journal of Public Health. Volume 28, Issue 2, Abr. 2018, pp. 269-275, doi.org/10.1093/eurpub/ckx235.

SCHMIEDER, Johannes; F.; VON WACHTER, Till; BENDER, Stefan. The effects of unemployment insurance on labor supply and search outcomes: Regression discontinuity estimates from Germany, IAB-Discussion Paper, $\mathrm{n}^{0}$. 4, Institut für Arbeitsmarkt- und Berufsforschung (IAB), Nürnberg. 2010. Disponivel em https://www.econstor.eu/handle/10419/32764. Acesso em 09 out. 2021.

SEHNBRUCH, Kirsten; CARRANJA, Rafael; CONTRERAS, Dante. Unemployment insurance in Chile: lessons from a high inequality developing country. Working paper, n. 54. International Inequalities Institute, London School of Economics and Political Science, London, UK. 2020. Disponível em: http://eprints.Ise.ac.uk/id/eprint/107824. Acesso em: 09 out. 2021.

SETTY, Ofer. Unemployment Insurance and Unemployment Accounts: The Best of Both Worlds, Journal of the European Economic Association, Volume 15, Issue 6, Dec. 2017, Pages 1302-1340. doi.org/10.1093/jeea/jvx005. 
ULYSSEA, Gabriel. Instituições e a informalidade no mercado de trabalho. Estudos Econômicos, São Paulo, v. 38, n. 3, pp. 525-556, set. 2008. http://dx.doi.org/10.1590/S0101-41612008000300004.

VELÁSQUEZ, Mario. Seguros de desempleo y reformas recientes en América Latina. CEPAL. Serie Macroeconomía del desarrollo, n. 99. Santiago de Chile, jan. 2010. Disponível em: https://repositorio.cepal.org/handle/11362/5465. Acesso em: 09 out. 2021.

ZYLBERSTAJN, Hélio; NETO, Giácomo Balbinotto. As Teorias de Desemprego e as Políticas Públicas de Emprego. Estudos Econômicos. Instituto de Pesquisas Econômicas, vol. 29, no. 1, pp. 129-149. 1999. Disponível em: https://www.revistas.usp.br/ee/article/view/117216 Acesso em: 09 out. 2021. 